\title{
APROXIMACIÓN AL BLOQUE DE CONSTITUCIONALIDAD Y DE CONVENCIONALIDAD EN EL SISTEMA DE JUSTICIA CONSTITUCIONAL COSTARRICENSE
}

\author{
Approach to the bloc of constitutionality \\ and conventionality in the Costa Rican constitutional \\ justice system
}

\author{
VÍCTOR OROZCO' \\ Universidad de Costa Rica \\ victorozcocr@gmail.com
}

Cómo citar/Citation

Orozco, V. (2019).

Aproximación al bloque de constitucionalidad y de convencionalidad en el sistema de justicia constitucional costarricense. Anuario Iberoamericano de Justicia Constitucional, 23(1), 175-206.

doi: https://doi.org/10.18042/cepc/aijc.23.06

\section{Resumen}

En el presente trabajo se pretende analizar los componentes del parámetro de regularidad constitucional en los ordenamientos jurídicos francés y costarricense. En el caso particular del sistema de justicia constitucional costarricense se analizan, con detalle, el nuevo paradigma del control de convencionalidad y sus implicaciones sobre ese parámetro.

1 Doctor en Derecho Constitucional por la Universidad de Castilla-La Mancha, coordinador de la Maestría en Justicia Constitucional de la Universidad de Costa Rica, letrado de la Sala Constitucional de la Corte Suprema de la República de Costa Rica. 


\section{Palabras clave}

Parámetro de constitucionalidad; control de convencionalidad; sistema de justicia constitucional costarricense; sistema de justicia constitucional francés.

\section{Abstract}

This paper aims to analyze the components of the parameter of constitutional regularity in the French and Costa Rican legal systems. In the particular case of the Costa Rican constitutional justice system, the new paradigm of conventionality control and its implications on this parameter are analyzed in detail.

\section{Keywords}

Constitutionality parameter; conventionality control; Costa Rican constitutional justice system; French constitutional justice system. 


\section{SUMARIO}

I. INTRODUCCIÓN. II. SOBRE EL BLOQUE DE CONSTITUCIONALIDAD: CONCEPTO, SIGNIFICADO Y CONTENIDOS. III. EL ORIGEN DEL BLOQUE DE CONSTITUCIONALIDAD Y LAS NORMAS QUE LO COMPONEN EN EL SISTEMA FRANCÉS: 1. El articulado de la Constitución de 1958. 2. El preámbulo de la Constitución de 1958. 3. La Declaración de Derechos del Hombre y del Ciudadano de 26 de agosto de 1789. 4. El preámbulo de la Constitución de 1946. 5. Los principios fundamentales reconocidos por las leyes de la República. 6. Los principios generales del derecho de valor constitucional. IV. EL BLOQUE DE CONSTITUCIONALIDAD Y SU RECEPCIÓN EN EL SISTEMA DE JUSTICIA CONSTITUCIONAL COSTARRICENSE: 1. La Constitución Política de la República de Costa Rica de 1949. 2. Las disposiciones del Reglamento de la Asamblea Legislativa que establecen trámites sustanciales en el procedimiento de formación de las leyes. 3. Los instrumentos internacionales sobre derechos humanos. V. CONCLUSIONES. BIBLIOGRAFíA.

\section{INTRODUCCIÓN}

En términos generales, el propósito de estas notas es analizar el reconocimiento efectivo del carácter normativo y supremo de la Constitución, así como las normas que componen el bloque de regularidad constitucional y convencional en el sistema de justicia constitucional costarricense. Lo anterior también nos obliga a realizar algunos comentarios sobre el origen de esta institución, que corresponde a la tradición jurídica francesa (en cuanto al bloque de constitucionalidad), y la manera en que con posterioridad fue receptada por el ordenamiento jurídico costarricense, señalándose además qué normas lo integran en cada sistema.

\section{SOBRE EL BLOQUE DE CONSTITUCIONALIDAD: CONCEPTO, SIGNIFICADO Y CONTENIDOS}

En esta oportunidad será analizado el origen del bloque de constitucionalidad, así como las normas que lo integran en el ordenamiento jurídico francés, y cuáles son las normas utilizadas por los jueces constitucionales para 
determinar si una norma es conforme o no con el derecho de la Constitución (que, como se profundizará en el último capítulo, en la tradición jurídica costarricense justamente se corresponde con el bloque de constitucionalidad, y que incluye, sin duda alguna, al derecho internacional sobre los derechos humanos). Sobre lo anterior, y en términos similares al caso de los preceptos que componen la norma constitucional, es preciso insistir sobre el carácter normativo y exigible de las normas que en cada ordenamiento jurídico se corresponden con el bloque de constitucionalidad, así como en el hecho de que, al igual que en el caso de las normas constitucionales, suponen la existencia de limitaciones y controles al ejercicio del poder. Así, en el caso particular de la Constitución, Aragón ha señalado:

Al margen de todo tipo de adjetivaciones, hablar de Constitución tiene sentido cuando se la concibe como un instrumento de limitación y control del poder. Efectivamente el control es un elemento inseparable del concepto de Constitución si se quiere dotar de operatividad al mismo, es decir, si se pretende que la Constitución se realice, en expresión, bien conocida de Hesse; o dicho en otras palabras, si la Constitución es norma y no un mero programa puramente retórico. El control no forma parte únicamente de un concepto «político» de Constitución, como sostenía Schmitt, sino de su concepto jurídico, de tal manera que sólo si existe control de la actividad estatal puede la Constitución desplegar su fuerza normativa y sólo si el control forma parte del concepto de Constitución puede ser entendida ésta como norma (1999: 12).

Pero la Constitución Política no solo es una norma jurídica (es decir, un instrumento normativo de control de poder), sino también es suprema y, como se ha insistido a lo largo de esta investigación, está situada en la cúspide del ordenamiento jurídico. Por este motivo ha sido dotada de mecanismos jurídicos y políticos para su defensa, los cuales no son equiparables, teniendo en cuenta que los controles jurídicos de la Constitución se originan a partir del reconocimiento de la existencia de un parámetro objetivo de valoración de todo el ordenamiento infraconstitucional (así como de los actos y las omisiones de los poderes públicos), que normalmente componen el texto de la Constitución y el bloque de constitucionalidad. De ahí que, tratándose del control jurídico de constitucionalidad (que utiliza como parámetro objetivo de enjuiciamiento de todo el ordenamiento constitucional el bloque de constitucionalidad), la actividad del órgano de justicia constitucional no es libre ni arbitraria, sino sometida a la Norma Básica, imputable a la misma; desde allí, explica Fernández Rodríguez (2003):

Los tribunales constitucionales suelen adoptar una postura que alarga los principios que recoge la Norma Fundamental, en especial a lo que atañe a los derechos y 
libertades. Tras períodos de una observancia estricta del texto constitucional, desde hace unos años los tribunales constitucionales han procedido a incidir en el sentido de una serie de principios antes más indeterminados y ahora de destacada importancia para examinar las leyes sometidas a control. Aludimos, por ejemplo, al principio de proporcionalidad o de racionalidad (2003: 63-64).

Un ejemplo de lo anterior, de acuerdo con el mismo autor, es Bélgica, en cuyo sistema jurídico, a la inicial limitación de las normas que integraban el parámetro de control de constitucionalidad (es decir, los artículos de la Constitución relativos al reparto de competencias entre el Estado, las comunidades y las regiones), fueron adicionados: el principio de igualdad, la interdicción de la discriminación y la libertad de enseñanza, en virtud de una reforma en el año 1988 (ibid.: 64). En Costa Rica, como hemos adelantado, en el art. 10 de la Constitución Política se ha encomendado a la Sala Constitucional de la Corte Suprema de Justicia la competencia de juzgar la conformidad de todo el ordenamiento infraconstitucional con respecto a la Constitución y al bloque de constitucionalidad.

A continuación se analizarán las disposiciones que componen el bloque de constitucionalidad, cuyo origen puede ser encontrado en el sistema francés, no sin antes repasar las normas que lo integran en cada ordenamiento jurídico.

\section{EL ORIGEN DEL BLOQUE DE CONSTITUCIONALIDAD Y LAS NORMAS QUE LO COMPONEN EN EL SISTEMA FRANCÉS}

De acuerdo con Fernández Rodríguez, el término bloque de constitucionalidad fue introducido por la doctrina francesa en los años setenta del siglo xx para referirse a lo que el Consejo de Constitucionalidad Francés ${ }^{2}$ ha denominado "principios y reglas de valor constitucional». Así en su jurisprudencia, el Consejo Constitucional reconoce todas las implicaciones del concepto sin utilizarlo expresamente (ibid.: 65). Se trata entonces de un conjunto normativo «que sirve de parámetro de referencia que engloba, al margen de la

2 La Constitución francesa de 1958, en su título VII, regula la composición y las funciones del Consejo Constitucional, el cual está integrado por nueve miembros. En sus decisiones, este órgano jurisdiccional puso fin a una prolongada tradición de soberanía ilimitada de la ley, al afirmar de manera tajante que el legislador «dans 1 exercise de sa compétence, du respect des principes et des regles de valeur constitutionnelle qui sante q'imposet a tous les organes de l'État», así como la expresión: «La loi [...] n'exprime la volonté générale que dan le respect de la Constitution» (Pardo Falcón, 1990: 111-112). 
vigente Constitución de 1958, el Preámbulo de la misma Constitución y, con él, por el hecho de que se cita en el mismo, la revolucionaria Declaración de Derechos del Hombre y del Ciudadano de 1789, el Preámbulo de la anterior Constitución, la de 1946 y los principios fundamentales reconocidos por las leyes de la República (a los que remite el Preámbulo de la Constitución de 1946) (op. cit.).

De esta manera, aunque en un inicio se pensaba que el Consejo Constitucional realizaría el control de constitucionalidad de manera marginal, ante la inexistencia de un parámetro de constitucionalidad suficientemente amplio, como para permitir al Consejo el desempeño de su función (en la medida en que el Texto Fundamental no poseía una parte dogmática de reconocimiento de derechos y libertades públicas), con posterioridad el Consejo desmintió esas previsiones iniciales al extender de manera considerable el parámetro y elaborar los cimentos de lo que luego la doctrina denominó bloque de constitucionalidad, lo cual trascendió las fronteras francesas (como se verá más adelante) para ser utilizado de manera regular en la teoría general del derecho constitucional ${ }^{3}$. Cabe mencionar, siguiendo a Roussillon, que la expresión bloque de constitucionalidad estrictamente proviene del derecho administrativo y, en concreto, del bloque de legalidad, que es bien conocido en las cuestiones administrativas (Roussillon, 2004: 49). Al respecto, Requejo Rodríguez sostiene que la doctrina francesa no hizo sino adaptar al ámbito constitucional el concepto administrativo de «bloque de legalidad» y actualizar la noción de «supralegalidad constitucional» ya presente en la obra de Hauriou. En este sentido, el primero se refería al parámetro utilizado por el Consejo de Estado francés

[...] para determinar la legalidad de los actos administrativos (ley, reglamentos, jurisprudencia) la segunda alude a una serie de principios que, sin estar recogidos en la Constitución vigente y sin existir siquiera una remisión en su favor, vinculan a las normas infra-constitucionales y al propio texto constitucional. La supralegalidad

3 Pardo Falcón, 1990: 116-117. En palabras del autor: «En realidad, la función de control de constitucionalidad quedaba concebida de una forma absolutamente marginal, para recurrir a ella esporádicamente. Esto era algo fácilmente apreciable en el caso de las leyes orgánicas y los reglamentos de las asambleas, normas sobre las cuales el Consejo Constitucional efectuaría un control preceptivo, pero agotando buena parte de su competencia en el momento de ejercerla, puesto que su propia naturaleza las hace especialmente perennes $y$, por tanto, poco proclives a excesivas modificaciones posteriores que pudieran dar lugar a un nuevo control al menos en períodos relativamente breves de tiempo. Algo parecido se pronosticaba en relación a los tratados internacionales, que tampoco deberían ser objeto de control por el Consejo con excesiva frecuencia» (pp. 113-114). 
constitucional operará, de este modo, no sólo como criterio de validez de normas legales sino también como parámetro de una reforma constitucional que será invalidada por el órgano competente, a semejanza de lo que venían realizando el Tribunal de Conflictos y el Consejo de Estado, si pretendiera revisar los principios que, de manera tácita o expresa, integran esa ilegitimidad constitucional (Requejo Rodríguez, 1997: 25).

De modo que el bloque de legalidad, de acuerdo con Favoreu, permitía designar, por encima de las leyes, todas las reglas que se imponían a la Administración en razón del principio de legalidad y que no compartían, ciertamente, la misma situación que las primeras, en la medida en que algunas poseían un origen jurisprudencial, particularmente las referidas a los principios generales del derecho. A partir de allí se ha desarrollado por la doctrina francesa la noción del bloque de constitucionalidad que parece adecuado para designar al conjunto «de los principios y reglas de valor constitucional» ( $\mathrm{Fa}$ voreu y Rubio Llorente, 1991: 20). Como se ha adelantado, en la actualidad el bloque de constitucionalidad lo constituyen: el articulado de la Constitución, el preámbulo de la Constitución de 1958 (y, con ello, la Declaración de los Derechos del Hombre y del Ciudadano de 26 de agosto de 1789, el preámbulo de 1946 y los principios fundamentales reconocidos por las leyes de la República), los principios generales del derecho de valor constitucional, la conciliación o armonización de las normas y principios constitucionales, y, entre las normas de rango infraconstitucional, la ordenanza orgánica relativa a las Leyes de Presupuestos y otras leyes y ordenanzas orgánicas u ordinarias.

A continuación serán analizados cada una de las normas que en el sistema francés componen el bloque de constitucionalidad, el tratamiento que han recibido por parte del Consejo Constitucional (y, en concreto, algunas de las decisiones en que ha reconocido el valor referido a esas disposiciones) y la manera en que la doctrina ha contribuido en la consolidación del bloque o en la delimitación de sus contenidos.

\section{EL ARTICULADO DE LA CONSTITUCIÓN DE 1958}

De acuerdo con Pardo Falcón, el articulado de la Constitución hace referencia a la parte dispositiva del Texto Fundamental, sin tener en consideración el preámbulo. En efecto, aquella reúne el contenido más importante de los que integran el bloque de constitucionalidad en lo que atañe a la materia de organización y funcionamiento de las autoridades públicas. En este sentido, la mayor parte de las normas jurídicas que componen el articulado de la Constitución regulan las instituciones fundamentales del Estado y, en ese sentido, es particularmente relevante el título V: «Des rapports entre le Parlement et 
le Gouvernement», en que se regula el funcionamiento del Parlamento (Pardo Falcón, 1990: 116-117). Dicho título ha sido utilizado por el Consejo Constitucional para controlar «la constitucionalidad de los reglamentos de las cámaras y de las leyes orgánicas, que se ocupan de tales instituciones, control que en ambos casos ha efectuado desde un primer momento, y que se ha ido sucediendo sin significativas variaciones cada vez que se ha producido alguna modificación de esas normas» (ibid.: 118) ${ }^{4}$. Cabe mencionar que el Consejo Constitucional se compone de dos tipos de miembros; es decir, los designados por las autoridades constitucionales competentes y los miembros de derecho. Asimismo, el presidente del Consejo Constitucional es nombrado entre ambos tipos de miembros y tiene voto de calidad (Bon, 2002: 399). En este sentido, y de conformidad con lo dispuesto por el art. 56 de la Constitución francesa ${ }^{5}$, los miembros designados son elegidos en forma discrecional por tres autoridades, el presidente de la República y los presidentes de las dos Cámaras legislativas, en tanto que los de derecho son aquellos que adquieren esa calidad en su condición anterior de expresidentes de la República (Pardo

4 Sobre el particular, el autor menciona las siguientes decisiones del Consejo Constitucional Francés D. 2DC de 17, 18 y 24 de junio de 1959 (AN), y D. 3DC de 24 y 25 de junio de 1959.

5 El art. 56 de la Constitución francesa de 1958 dispone: «Le Conseil Constitutionnel comprend neuf membres dont le mandat dure neuf ans et n'est pas renouvelable. Le Conseil Constitutionnel se renouvelle par tiers tous les trois ans. Trois des membres son nommés par le Président de la République, trois par le Président de l'Asamblée Nationale, trois par le Président du Sénat [...]».

Cabe mencionar que esta disposición ha sido modificada en virtud de la Ley Constitucional 2008-724, de 23 de julio, la cual entrará en vigor en las condiciones fijadas por las leyes y leyes orgánicas necesarias para su aplicación. De esta manera, y en virtud de esa ley constitucional, el texto del art. 56 ídem será el siguiente:

«ARTÍCULO 56. El Consejo Constitucional estará compuesto por nueve miembros, cuyo mandato durará nueve años y no será renovable. El Consejo Constitucional se renovará por tercios cada tres años. Tres de la Asamblea Nacional y tres por el Presidente del Senado. El procedimiento previsto en el último párrafo del artículo 13 será aplicable a sus miembros serán nombrados por el Presidente de la República, tres por el Presidente de estos nombramientos. Los nombramientos realizados por el Presidente de cada Cámara serán sometidos únicamente al dictamen de la comisión permanente competente de la Cámara correspondiente.

Además de los nueve miembros arriba mencionados, los ex-Presidentes de la República serán miembros vitalicios de pleno derecho del Consejo Constitucional.

El Presidente será nombrado por el Presidente de la República. Tendrá voto de calidad en caso de empate». 
Falcón, 1990: 77) ${ }^{6}$. Entre las normas constitucionales que con más frecuencia ha utilizado el Consejo Constitucional francés en el ejercicio de sus atribuciones, cabe mencionar las siguientes (de acuerdo con Pardo Falcón): el art. 64, que consagra el principio de independencia judicial y de la inamovilidad de los magistrados de carrera; el art. 65, que establece el principio de garantía de la libertad individual a cargo de la autoridad judicial; el art. 2.1, que alude al principio de indivisibilidad de la República; el art. 4, relativo al principio de la libre formación de grupos políticos; el art. 72.2, que proclama el principio de libre administración de las colectividades territoriales, y el art. 3.3, en que se reconoce el derecho de igualdad en el sufragio (ibid.: 118-119).

Finalmente, y de acuerdo con el mismo autor, han sido excluidas del bloque de constitucionalidad las siguientes disposiciones del articulado de la Constitución: 1 y de 77 a 88, los cuales han perdido su vigencia en cuanto se referían a la extinta Comunidad (ibid.: 119) ${ }^{7}$. También menciona el autor que en algunas ocasiones el Consejo Constitucional ha preferido aplicar una disposición de la Declaración de 1789 sobre el texto de la Constitución, que puede tener un sentido similar, como es el caso del art. 2.1, en que se proclama el derecho de igualdad (Roussillon, 2004: 51).

6 Cabe mencionar que ni la Constitución de 1958 ni la Ley Orgánica sobre el Consejo Constitucional someten el nombramiento de los miembros de este órgano a algún requisito, de ahí que pueda ser escogida cualquier persona que disfrute de los derechos civiles y políticos, no necesariamente un profesional en derecho. Asimismo, el mandato de cada consejero tiene una duración de nueve años sin posibilidad de reelección. Ahora bien, en lo que atañe a los miembros de derecho, la doctrina ha considerado que su inclusión obedece a una motivación doble y hasta cierto punto paradójica: «En efecto, por un lado se pretendía destacar de este modo la continuidad del régimen republicano por encima de avatares políticos y modificaciones constitucionales, rindiéndose al mismo tiempo un homenaje a quienes habían sido en su momento Presidentes de la Cuarta República, Vicent Auriol y René Coty; pero, por otro lado, esta deferencia también tenía como finalidad fundamental, según algunos, el apartar definitivamente a ambos ex presidentes de la vida política activa, asegurándoles un retiro digno con su integración en la nueva institucional constitucional». Por su parte, el presidente del Consejo Constitucional es elegido a través de una decisión personal de quien ocupe el cargo de presidente de la República, de acuerdo con el párr. 3. ${ }^{\circ}$ del art. 56 de la Constitución francesa de la Quinta República.

7 Sobre el particular, Luis Favoreu afirmó: «Todas las disposiciones de la Constitución tienen la misma fuerza. Ahora bien, hay que señalar que los artículos 77 a 88 —relativos a la Comunidad, que ha desaparecido en 1960, con el acceso a la independencia de los antiguos territorios de África- ya no son aplicables» (Favoreu y Rubio Llorente, 1991: 26). 


\section{EL PREÁMBULO DE LA CONSTITUCIÓN DE 1958}

De acuerdo con Rousseau, el valor normativo de la Declaración de 1789 y el preámbulo de la Constitución de 1946 han sido objeto de gran controversia doctrinal hasta el año 1971. Por un lado, Carré de Malberg y Eximen habían insistido en que esos textos no poseían ningún valor normativo, sino que suponían sendas declaraciones de buenas intenciones morales y filosóficas, de ahí que constituían, en su criterio, un texto literario más que un texto normativo (Rousseau, 2010: 92). Por el otro, varios autores han sostenido (entre ellos Hauriou y Duguit) que esas declaraciones sí poseen fuerza normativa y el mismo valor que el texto constitucional. Por esa razón, estos textos imponían el deber al legislador de respetar el contenido de sus disposiciones (op. cit.). En la actualidad, el preámbulo de la Constitución de 1958, en su primer párrafo, proclama lo siguiente: «Le peuple français proclame solennellement son attachement aux Droit de l'homme et aux principes de la souveranité nationale tels qu'ils ont été définis par la Déclaration de 1789, confirmée et complétee par le préambule de la Constitution de 1946»

Sobre el contenido de esa disposición, autores como Pardo Falcón afirman que inicialmente estaba desprovisto de todo valor normativo y constitucional, de acuerdo con el Texto Fundamental de 1958. En palabras del autor:

El tema — que se plantea con claridad absoluta durante los debates constitucionalesqueda resuelto cuando el comisario del Gobierno, invocando el fantasma del gobierno de los jueces, convence a los miembros del Comité Consultivo Constitucional que habían introducido una enmienda concediéndole dicho valor del extraordinario y desaconsejable poder que se atribuiría al Consejo Constitucional en tal caso, al facultarle para controlar la actividad legislativa también en materia de derechos y libertades. La enmienda es retirada y en el seno del Comité parece hacerse firme la idea de que el Preámbulo de la Constitución de 1958 no va a gozar del mismo valor normativo que las disposiciones incluidas dentro del texto articulado (Pardo Falcón, 1990: 120).

En vista de que dicha tesis prevaleció de manera pacífica entre quienes redactaron la Constitución francesa de la V República, Pardo Falcón supone que ni el Comité ni el Gobierno consideraron necesario diseñar en el texto constitucionalalgunadisposiciónqueexcluyeraexpresamentedelcontroldeconstitucionalidad la materia contenida en el preámbulo de la Constitución, como se verificó en la Norma Fundamental de 1946 (op. cit. $)^{8}$. Pues bien, tan pronto

8 De acuerdo con el autor, en ese sentido se manifestaron Ch. Eisenmann y L. Hamon en el Coloquio de Heidelberg, celebrado en 1962 («La juridiction constitutionnelle en drot français», Colloque de Heidelberg, 1962, pp. 231-291). 
como las circunstancias políticas lo permitieron, el Consejo Constitucional atribuyó valor constitucional al preámbulo de 1946 mediante la famosa Decisión del 16 de julio $1971^{9}$, a la Declaración de 1789 mediante la Decisión del 27 de diciembre de 1973 y, de manera general, a todos los textos referidos en el preámbulo de la Constitución de 1958 (Rousseau, 2010: 94). Así, en la Decisión de 16 de julio 1971, el Consejo Constitucional se pronunció sobre una posible violación de la libertad de asociación y anuló una disposición legislativa por ser contraria a uno de los principios fundamentales reconocidos por las leyes de la República contenidos indirectamente en el mismo (Pardo Falcón, 1990: 122 $)^{10}$. De acuerdo con Rivero, desde ese momento la Constitución francesa se ha duplicado en tamaño por la voluntad del Consejo Constitucional (Rivero, 1984: 168), pues con la aludida decisión se integraron en el bloque de constitucionalidad no solo el preámbulo de 1958 propiamente dicho sino también otros textos jurídicos de contenido mucho más denso, como son: la Declaración de Derechos del Hombre y del Ciudadano de 1789 y el preámbulo de la Constitución de 1946 con los «principios fundamentales reconocidos por las leyes de la República y los principios políticos económicos y sociales particularmente necesarios a nuestro tiempo a los que este último hace referencia» (Pardo Falcón, 1990: 122). De esta manera nació en el sistema francés un complejo sistema de fuentes constitucionales en materia de derechos fundamentales y libertades públicas, no solo por su nomenclatura sino por los momentos históricos en que esos textos fueron redactados, que plantea severos problemas al intérprete y al operador jurídico en el momento

9 Sobre lo anterior, Francisco Fernández Segado ha comentado: «Sería el propio Conseil quien, en la motivación jurídica de sus decisiones, iba a ir precisando las normas de référence que habían de servirle de base, de canon, de parámetro para su fiscalización constitucional. Como ya se ha puesto de relieve en diversos momentos, el hito fundamental de este proceso lo encontramos en la tantas veces citada Decisión de 16 de julio de 1971. En ella (considerando segundo), el juez constitucional se refería por vez primera a los "principios fundamentales reconocidos por las leyes de la República", expresamente mencionados por el constituyente en la Cuarta República en el primer párrafo del Preámbulo de la Constitución de 1946 y solemnemente reafirmados por el Preámbulo de la Carta de 1958» (Fernández Segado, 2009: 520-521).

10 En palabras de Jean Rivero: «Le Conseil Constitutionnel a-t-il rendu, le 16 juillet 1971, sa décision Marbury v. Madison en affirmant l'inconstitutionnalité des disposition adoptées par le Parlement qui instituaient une forme de contrôle préalable sur les déclarations d'association? Il serait imprudent de l'affirmer. Pourtant, la décision existe, et c'est précisément sur la violation d' un des "principes fondamentaux reconnus par les lois de la République” que se fonde la censure prononcée par le Conseil». Véase Rivero(1987). 
de su aplicación (ibid.: 123). Sobre lo anterior, Rubio Llorente ha sostenido: «Ya esta integración en la Constitución de dos textos que responden a espíritus y concepciones muy distintos, y entre los que inevitablemente se producen antinomias, bastaría para hacer del bloc un cuerpo más bien deforme, junto al cual el Título I de nuestra Constitución pueda ser considerado, sin exageración, como un monumento de claridad cartesiana [...]» (Rubio Llorente, 1997: 107).

Así, y siguiendo con el mismo autor, esta extensión de la noción de las normas constitucionales y su indefinición plantea en el sistema francés profundos problemas de interpretación, de manera que haría desplazar de los países con jurisdicción constitucional los temas clave del control, por el de determinar cuál es, a fin de cuentas, la norma constitucional con la cual debe ser valorada la conformidad del ordenamiento infraconstitucional, es decir, cuál es la norma constitucional que sirve como parámetro de control (ibid: 107-108 $)^{11}$. En consecuencia la expresión bloc de constitutionnalité no es para Rubio Llorente la denominación de una categoría, «sino el enunciado de un problema, y de un problema, además, que no hace referencia alguna, ni de lejos ni de cerca, a la función de delimitación competencial que realizan al menos parte de las normas (para algunos autores y en algunas sentencias del Tribunal Constitucional, todas las normas) que entre nosotros se consideran parte del bloque de la constitucionalidad» (ibid.: 108). Todas estas ideas son

11 Sobre lo anterior, Favoreu ha destacado la labor desplegada por el Consejo Constitucional francés, justamente en la delimitación de las normas y los principios que integran el bloque de constitucionalidad, de modo que, en su criterio, la lista de las normas que actualmente componen el bloque de constitucionalidad francés está cerrada. En palabras del autor: «Por tanto la composición actual del bloque de constitucionalidad es novedosa y está integrada por cuatro partes, por cuatro categorías de normas: están las disposiciones de la Constitución de 1958, es decir, desde el artículo 1 al 92 y su Preámbulo, algunas de cuyas disposiciones concretas han sido ya objeto de aplicación, como la relativa al derecho a la autodeterminación de los pueblos de ultramar. Pero a estas disposiciones hay que añadir las categorías a las que también hace referencia el Preámbulo de 1858, es decir, hay que añadir los diecisiete artículos de la Declaración de 1789, más los diecisiete párrafos del Preámbulo de 1946, más los principios fundamentales reconocidos por las leyes de la República. La lista está cerrada no hay otra cosa. En algún momento anterior quizá podrían haberse añadido otras normas, pero hoy esta hipótesis debe quedar ya definitivamente excluida. Así lo pone claramente de manifiesto una comunicación que recientemente acaba de exponer el profesor Vedel: existen cuatro categorías de normas de referencia. Eso es todo. Entonces, veamos cada una de las categorías que integran esas normas de referencia y después las normas que quedan excluidas» (Favoreu y Rubio Llorente, 1991: 61-62). 
compartidas en esta investigación, de ahí que no sea posible equiparar la noción del bloque de constitucionalidad que se maneja en el sistema de justicia constitucional francés frente a la que se plantea en el ordenamiento jurídico español.

\section{LA DECLARACIÓN DE DERECHOS DEL HOMBRE Y DEL CIUDADANO DE 26 DE AGOSTO DE 1789}

A pesar de que desde el año 1973 el Consejo Constitucional había afirmado que la Declaración de Derechos del Hombre y del Ciudadano de 26 de agosto de 1789 también integraba el bloque de constitucionalidad (particularmente, desde la D. 51DC de 27 de diciembre de 1973, así como en otras decisiones posteriores: D. 56.DC de 23 de julio de 1975, D. 67DC de 15 de julio de 1976, D. 83DC de 20 de julio 1977 y D. 101DC de 17 de enero de 1979), a finales de la década de los setenta se suscitó una discusión doctrinal entre quienes consideraban que la aludida declaración, en su totalidad, poseía valor constitucional y quienes se lo atribuían únicamente a determinadas disposiciones (Pardo Falcón, 1990: 123) ${ }^{12}$. En este sentido, dicha polémica fue aclarada por el Consejo Constitucional, con la D. 132 DC de 16 de enero de 1982, en que afirmó: «Le peuple français a approuvé des textes conférant valeur constitutionnelle aux principes et aux droits proclamés en 1789»; lo anterior, sin hacer ningún tipo de distinción sobre las disposiciones de la Declaración, otorgándose pleno valor constitucional a sus normas (op. cit.. $)^{13}$.

12 Sobre el particular, Luis Favoreu ha sostenido: «El conjunto de las disposiciones (arts. 1 a 17) de la Declaración de 1789 es aplicable. En un primer momento, ciertos autores sostuvieron que únicamente algunas tenían valor de Derecho positivo y eran susceptibles de recibir aplicación. Sin embargo, el Consejo Constitucional no hace ninguna distinción entre ellas y, además, ha aceptado decidir prácticamente sobre la base de todas ellas. Por otra parte, observemos, de paso, que las prescripciones contenidas en los artículos 1 a 17 de la Declaración son comparables a las que figuran en el Capítulo II de la Constitución española (arts. 14 al 38)» (Favoreu y Rubio Llorente, 1991: 20). Sobre esta disputa doctrinal y su posterior resolución por parte del Consejo Constitucional francés en el sentido de que todas las disposiciones de la Declaración de Derechos del Hombre y del Ciudadano de 26 de agosto de 1789 tienen valor constitucional y fuerza normativa, Dominique Rousseau ha comentado: «En effet, si la doctrine a pu, un moment, router de la constitutionnalité de ce texte au motif que certaines de ses dispositions ne concernent ni les droits de l'homme, ni les principes de la souveraineté nationale, ou qu'elles son contredites par les nouveaux principes de 1946, il est clair, notamment depuis la décision du 16 janvier 1982, que chacun des 17 articles de la Déclaration de 1789 a une valeur constitutionnelle» (Rousseau, 2010: 94). 
De lo anterior, Favoreu ha concluido que «el lugar ocupado por la Declaración en el seno del bloque de constitucionalidad es, sin duda alguna, tan importante al menos como el de sus otros componentes, contrariamente a lo que se podría sostener antes de 1981-1982: el Consejo Constitucional, en su decisión de 16 de enero de 1982, ha confirmado que, a pesar de su edad, la Declaración de derechos del hombre tiene una fuerza, al menos igual a la del Preámbulo de 1946» (Favoreu y Rubio Llorente, 1991: 27-28). De esta forma, el Consejo Constitucional francés ha declarado numerosas inconstitucionalidades por violación de la Declaración de Derechos del Hombre y del Ciudadano de 26 de agosto de 1789, convirtiéndose en el segundo instrumento más utilizado tras el propio texto del articulado constitucional y el primero en materia de derechos fundamentales y libertades públicas (Pardo Falcón, 1990: 123).

\section{EL PREÁMBULO DE LA CONSTITUCIÓN DE 1946}

El Consejo Constitucional francés, en la D. 54 DC de 15 de enero de 1975, aplicó por primera ocasión los principios políticos, económicos y sociales particularmente necesarios en nuestro tiempo, recogidos en el preámbulo de 1946, y les otorgó rango constitucional. En la práctica, el Consejo Constitucional ha utilizado la expresión "principios enumerados en la Constitución de 1946» o la de preámbulo de la Constitución de 1946 para referirse a esta categoría (ibid.: 125) ${ }^{14}$. De acuerdo con Pardo Falcón, en la decisión anterior

14 El preámbulo de la Constitución francesa de 1946 es el siguiente:

Apenas alcanzada por los pueblos libres la victoria sobre los regímenes que pretendieron sojuzgar y degradar la persona humana, el pueblo francés proclama, una vez más, que todo ser humano, sin distinción de raza, de religión o de creencias, posee derechos inalienables y sagrados. Reafirma solemnemente los derechos y libertades del hombre y del ciudadano, consagrados por la Declaración de Derechos de 1789, y los principios fundamentales reconocidos por las leyes de la República. Proclama, además, como particularmente necesarios en nuestra época, los siguientes principios políticos, económicos y sociales: La ley garantiza a la mujer, en todas las esferas, derechos iguales a los del hombre. Todo hombre perseguido a causa de su acción en favor de la libertad goza del derecho de asilo en los territorios de la República. Todos tienen el deber de trabajar y el derecho de obtener un empleo. Nadie puede ser perjudicado en su trabajo o en su empleo a causa de sus orígenes, de sus opiniones o de sus creencias. Todo hombre puede defender sus derechos y sus intereses mediante la acción sindical $\mathrm{y}$ adherirse al sindicato de su elección. El derecho de huelga se ejerce con arreglo a las leyes que lo reglamentan. Todo trabajador participa, a través de sus delegados, en la determinación colectiva de las condiciones de trabajo y en la gestión de las empresas. Todo bien y toda empresa cuya explotación posea o adquiera los caracteres de un 
(y, particularmente, en la D. 105 DC de 25 de julio de 1789, «droit de grèvè à la radio et à la televisión", que constituye la primera de anulación con base en alguno de estos principios), el Consejo Constitucional da por terminada la discusión y la corriente que imperaba en la doctrina francesa, en el sentido de negar el valor jurídico de las disposiciones del preámbulo de la Constitución de 1946. Lo anterior, teniendo en cuenta la imprecisión y la vaguedad de los principios que proclamaba el preámbulo (ibid.: 123).

\section{LOS PRINCIPIOS FUNDAMENTALES RECONOCIDOS POR LAS LEYES DE LA REPÚBLICA}

Los principios fundamentales reconocidos por las leyes de la República constituyen una nueva categoría jurídica que ha adquirido valor constitucional por la mención que con respecto a ella realiza el preámbulo de la Constitución de 1946, tras la remisión efectuada con anterioridad por el preámbulo de la Constitución de 1958. Se trata, siguiendo a Pardo Falcón, de una remisión de

servicio público nacional o de un monopolio de hecho debe pasar a ser propiedad de la colectividad. La Nación proporciona al individuo y a la familia las condiciones necesarias para su desarrollo. Garantiza a todos, y en especial al niño, a la madre y a los trabajadores ancianos, la protección de su salud, de su seguridad material, de su descanso y de su tiempo libre. Todo ser humano que, en razón de su edad, de su estado físico o mental o de la situación económica, se encuentre incapacitado para trabajar, tiene derecho a obtener de la colectividad medios de existencia decorosos. La Nación proclama la solidaridad y la igualdad de todos los franceses ante los gravámenes resultantes de calamidades nacionales. La Nación garantiza la igualdad del acceso del niño y del adulto a la instrucción, a la formación profesional y a la cultura. La organización de la enseñanza pública gratuita y laica en todos los niveles es un deber del Estado. La República Francesa, fiel a sus tradiciones, se conforma a las reglas del derecho público internacional. No emprenderá ninguna guerra con fines de conquista y no empleará jamás sus fuerzas contra la libertad de ningún pueblo. Con tal que haya reciprocidad, Francia acepta las limitaciones de soberanía necesarias para la organización y defensa de la paz. Francia forma con los pueblos de ultramar una Unión fundada en la igualdad de los derechos y de los deberes, sin distinciones de raza ni de religión. La Unión Francesa se compone de naciones y pueblos que ponen en común o coordinan sus recursos y sus esfuerzos para desarrollar sus respectivas civilizaciones, acrecentar su bienestar y proveer a su seguridad. Fiel a su misión tradicional, Francia se propone conducir a los pueblos que ha tomado a su cargo a la libertad de administrarse a sí mismos y de tratar democráticamente sus propios asuntos; desechando todo sistema de colonización basado en la arbitrariedad, garantiza a todos la igualdad de acceso a las funciones públicas y el ejercicio individual o colectivo de los derechos y libertades precedentemente proclamados o confirmados». 
segundo grado (ibid:: 128). De acuerdo con el mismo autor, la incorporación de estos principios en el preámbulo de la Constitución de 1946 constituye un logro de la derecha francesa, que tenía la intención de elevar a rango constitucional, por esa vía indirecta, la libertad de enseñanza, que con anterioridad no disfrutaba de ningún reconocimiento de derecho positivo. Por su lado, la izquierda acabó admitiendo la introducción del término, para lograr la aprobación del nuevo texto constitucional y bajo la consideración de que esa formulación sería considerada como un mero homenaje de los legisladores de la Tercera República, desprovista entonces de toda relevancia jurídica (ibid.: 128-129).

Sin embargo, y como se expuso con anterioridad, el Consejo Constitucional francés, en su D. 44DC de 16 de julio de 1971, anuló de una ley de asociación una disposición que contravenía el principio de la libertad de asociación, que provenía de otra ley sobre la misma materia del año 1901, al considerarla contraria a los principios fundamentales señalados en el preámbulo de 1946. Con posterioridad, en la D. 87DC de 23 de noviembre de 1977 el Consejo confirió el rango constitucional a la libertad de enseñanza y, con ello, confirmó las expectativas de sus valedores en el referido proceso constituyente (ibid.: 129).

Como se puede suponer, las decisiones del Consejo Constitucional tendentes a dotar de rango constitucional a los principios fundamentales reconocidos por las leyes de la República generaron gran polémica doctrinal y reiteradas inquietudes, en cuanto al alcance de esos principios, sus contenidos y, todavía más, su delimitación. Sobre el particular, Rivero formuló tres grandes preguntas: «Quelles République? quelles lois? que sont les principes fondamentaux?» (Rivero, 1984: 265) ${ }^{15}$. Abundando en esto, el mismo Rivero ha sostenido: «Des multiples questions que pose la promotion des "principes fondamentaux reconnus par les lois de la République " dans la hiérarchie des normes juridiques, deux son d'ores et déjà résolues. Et c'est précisément des réponses qu'elles ont reçues que découlent tous les problèmes qui restent à résoudre» (ibid:: 154).

15 Esta situación ha sido descrita por Henry Roussillon del siguiente modo: «Avec cette deuxième catégorie de principes, aujourd'hui "marginaux" pour le doyen Favoreu, voulue essentiellement par le MRP précisément à cause de son ambiguïté et de la possibilité que'elle offrait de consacrer un droit particulièrement contesté à l'époque, la liberté d'enseignement, nous nous heurtons à une triple question comme l'a fort bien montré J. Rivero: quels Principes? quelles Lois? quelle République?» (Roussillon, 2004: 55). 
Sobre los cuestionamientos anteriores, Rousseau considera que la decisión del Consejo Constitucional francés (D. 244DC de 20 de julio de 1988) aportó varios elementos para resolverlos (Rousseau, 2010: 95); tales cuestionamientos son:

- Los principios fundamentales deben encontrarse recogidos en normas con rango de ley, perfectamente identificables. Sobre lo anterior, Pardo Falcón advierte de que el Consejo Constitucional no aplica este criterio con uniformidad, pues en algunas ocasiones ha declarado la anulación de preceptos por la mera violación de los principios fundamentales reconocidos por las leyes de la República, sin vincularlos a ningún texto concreto. Ello se ha producido en situaciones en las cuales es difícil conceptualizar el principio fundamental en una determinada disposición, como son los casos de la libertad individual y del derecho de defensa, en los cuales también se debe tener en cuenta su mayor grado de notoriedad y evidencia; en otras ocasiones, cuando la aplicación del principio puede generar mayor controversia, el juez constitucional sí precisa determinar la norma concreta que lo contiene (Pardo Falcón, 1990: 130).

- El principio extraído de la ley de la República es el que tiene rango constitucional, no la ley en sí misma. De lo contrario, advierte Pardo Falcón:

[...] el legislador quedaría vinculado por su redacción concreta sin disponer prácticamente de margen alguno de maniobra [...]. Por consiguiente, en este caso el bloque de constitucionalidad está integrado por principios y no por normas propiamente dichas, lo que explica la utilización por el Consejo Constitucional, como ya hemos dicho, de la expresión principios y reglas de valor constitucional, que incluye también a estos principios fundamentales reconocidos por las leyes de la República (ibid.: 131).

- El significado de República: sobre el particular, la doctrina ha determinado que deben ser tomados en consideración los principios fundamentales recogidos durante la legislación producida en las tres primeras Repúblicas (op. cit.). Al respecto, Favoreu ha sostenido:

En primer lugar, se ha descartado la asimilación entre tradición republicana y principio fundamental reconocido por las leyes de la República: La tradición republicana no podrá ser invocada con provecho para sostener que un texto legislativo que la contradiga es contrario a la Constitución salvo en la medida en dicha tradición haya engendrado un principio fundamental reconocido por las leyes de la República [...]. Sin embargo, se ha establecido una conexión entre tradición republicana y principios fundamentales reconocidos por las leyes de la República, lo que confirma el hecho de que éstos sólo pueden derivar de las leyes de la República, como 
ocurre en la misma decisión, a partir de la cual se pueden enumerar las condiciones requeridas para que haya un principio fundamental reconocido por las leyes de la República (Favoreu y Rubio Llorente, 1991: 31).

- La exclusión de las leyes de la Cuarta República: lo anterior, teniendo en consideración que la remisión a los principios fundamentales reconocidos por las leyes de la República fue realizada justamente por medio del preámbulo de la Constitución de 1946, que establecía la Cuarta República, con lo que no podían ser tomadas en cuenta las leyes que se produjeron en ese período (Pardo Falcón, 1990: 131). De ahí que, siguiendo a Favoreu: «Esta legislación republicana es la aprobada antes de la entrada en vigor del Preámbulo de 1946 (es decir, antes del 27 de octubre de 1946), lo que pone fin a ciertas hipótesis doctrinales según las cuales los principios reconocidos podrían derivar de leyes posteriores a esta fecha» (Favoreu y Rubio Llorente, 1991: 32).

- El valor constitucional «independiente» de los principios fundamentales reconocidos por las leyes de la República: en virtud del cual, de acuerdo con el Consejo Constitucional francés, no es necesario que estén recogidos de manera simultánea tanto en la Declaración de Derechos del Hombre y del Ciudadano de 26 de agosto de 1789 como en las leyes de la República (Pardo Falcón, 1990: 132).

En suma, y de acuerdo con Pardo Falcón:

[Los] principios fundamentales reconocidos por las leyes de la República constituyen sin duda una de las fuentes normativas más complejas de todas aquéllas a que hace expresamente referencia el Preámbulo de la Constitución de 1958. En realidad, junto a la excesiva libertad de apreciación que deja en manos del juez constitucional [...] el inconveniente principal que se ha achacado a esta categoría jurídica es el que vacía en la práctica las competencias del legislador enumeradas en el art. 34 de la Constitución, en concreto por lo que se refiere al establecimiento de garantías para el ejercicio de libertades públicas.

$\mathrm{Al}$ respecto, Favoreu advierte sobre la poca importancia cuantitativa que tienen los principios fundamentales reconocidos por las leyes de la República en las decisiones del Consejo Constitucional francés (de acuerdo con el mismo autor, a fecha de 1989 la invocación de estos principios ante el Consejo Constitucional apenas representaba el 3,7 \% de los casos planteados, en tanto que de los supuestos de anulación la utilización de esos principios apenas representaba el $4 \%$ de los analizados). De ahí, considera este autor que tales principios apenas constituyen «elementos marginales del bloque de constitucionalidad» (Favoreu y Rubio Llorente, 1991: 30). 
Ahora bien, entre los principios fundamentales reconocidos por las leyes de la República que han sido desarrollados por el Consejo Constitucional francés, es preciso mencionar los siguientes: la libertad de asociación (D. 7144DC de 16 de julio de 1971), los derechos de defensa (D. 76-70DC de 2 de diciembre de 1976), la libertad individual (D. 76-75DC de 12 de enero de 1977), la libertad de enseñanza (D. 77-87DC), la independencia de la jurisdicción administrativa (D. 80-119DC de 22 de julio de 1980), la independencia de los profesores de universidad (D. 83-165DC de 20 de enero de 1984), la competencia exclusiva de la jurisdicción administrativa en materia de anulación de actos de la autoridad pública (D. 86-224DC de 23 de enero de 1987), así como la autoridad judicial como guardiana de la propiedad privada (D. 89-256DC de 25 de julio de 1989) (ibid.: 32 y 33).

\section{LOS PRINCIPIOS GENERALES DEL DERECHO DE VALOR CONSTITUCIONAL}

Con esta categoría se hace referencia a los principios que han sido utilizados por el Consejo Constitucional para sustentar sus decisiones de manera directa, sin utilizar ningún texto constitucional. De acuerdo con Pardo Falcón, se trata de una expresión de origen doctrinal que sirve para aludir a los que el Consejo Constitucional ha empleado como «principios de valor constitucional» (Pardo Falcón, 1990: 134-135). Entre los principios constitucionales que de acuerdo con el mismo autor pueden ser reconducidos a esta categoría, se podría mencionar los siguientes: el principio de separación de Poderes (D. 104DC de 23 de mayo de 1979), el principio de continuidad en el servicio público (D. 105DC de 25 de julio de 1979), y el derecho de defensa en materia penal (D. 182DC de 18 de enero de 1985 y D. 184DC de 29 de diciembre de 1984) (ibid.: 135). Cabe mencionar que el Consejo Constitucional francés también ha integrado en el bloque de constitucionalidad algunas disposiciones de rango infraconstitucional con motivo del control de los reglamentos de las Cámaras. Así se deduce con toda claridad del contenido de las decisiones D. 2 DC de 17, 18 y 24 de junio de 1959, D. 28 DC de 8 de julio de 1966, D. 37 DC de 20 de noviembre de 1969 y D. 86 DC de 3 de noviembre de 1977 , en cuya razón incluyó dentro del bloque de constitucionalidad varias ordenanzas relativas a las condiciones de elegibilidad y a las incompatibilidades parlamentarias, así como sobre las materias reservadas a la ley ordinaria (ibid.: 142-143). También ha incluido el Consejo Constitucional francés en el bloque de constitucionalidad la Ordenanza Orgánica 59-2 de 2 de enero de 1959, relativa a las Leyes de Finanzas. En este sentido, y según lo ha sostenido el Consejo en la D. 8 DC de 11 de agosto de 1960, la aludida ordenanza forma parte del bloque en todos aquellos supuestos en que se discuta la constitucionalidad de ese tipo de leyes (ibid.: 142-142). 
Una vez desarrolladas las disposiciones que de acuerdo con el Consejo Constitucional francés componen el bloque de constitucionalidad o el parámetro para juzgar la compatibilidad o la regularidad constitucional del ordenamiento jurídico, es preciso mencionar las disposiciones que han sido excluidas de la configuración francesa del bloque de constitucionalidad, a saber: el derecho internacional, tanto general como convencional; los reglamentos parlamentarios; la costumbre constitucional; las decisiones del Consejo Constitucional, y, por último, las leyes ordinarias y los principios generales del derecho de valor legislativo.

\section{EL BLOQUE DE CONSTITUCIONALIDAD Y SU RECEPCIÓN EN EL SISTEMA DE JUSTICIA CONSTITUCIONAL COSTARRICENSE}

Pues bien, una vez expuestas las nociones del bloque de constitucionalidad en el sistema francés, así como las normas que lo componen, de seguido será examinada la concepción del bloque en el ordenamiento jurídico costarricense, que, como se ha adelantado, se corresponde con lo que la doctrina costarricense ha denominado el derecho de la Constitución y que incluye al derecho internacional de los derechos humanos en el nuevo paradigma del control de convencionalidad (Hernández Valle, 1993).

Es claro entonces que el derecho de la Constitución vincula a todas las autoridades y a los Poderes públicos. En este sentido, y en el caso particular de los jueces ordinarios, Solano Carrera ha sostenido que tales funcionarios, por haber rendido el juramento constitucional al asumir el cargo, han prometido observar la Constitución y las leyes, de forma que son los principales obligados a respetar y aplicar ambos tipos de normativa, cada cual en su lugar, es decir, guardando la jerarquía de cada cual, la Constitución y las leyes (Solano Carrera, 1995: 35). Así, en estas líneas será desarrollada la manera en que la fuerza normativa de la Constitución vincula a las autoridades públicas, y la medida en que el derecho de la Constitución sirve como parámetro para analizar la adecuación o la conformidad de todo el ordenamiento jurídico costarricense con respecto al Texto Fundamental.

Así pues, a continuación se realizará una aproximación sobre las normas que en el ordenamiento jurídico costarricense componen el bloque de constitucionalidad o el derecho de la Constitución; tales son, el texto de la Constitución Política de la República de Costa Rica, el derecho internacional de los derechos humanos, y ciertas disposiciones del Reglamento de la Asamblea Legislativa que establecen trámites sustanciales en el procedimiento de aprobación de las leyes. Al respecto, la inobservancia de alguna de estas formalidades sustanciales en el Reglamento de la Asamblea Legislativa, como 
se verá con alguna profundidad más adelante, puede dar lugar a una declaratoria de inconstitucionalidad del precepto infraconstitucional cuestionado, si con motivo de su aprobación se han vulnerado dichos trámites sustanciales, especialmente vinculados con el principio democrático y de publicidad, los cuales deben ser apreciados por la Sala Constitucional en el caso concreto de que se trate. De ahí que no todas las disposiciones del Reglamento de la Asamblea Legislativa integran el derecho de la Constitución, sino aquellas que desarrollan en el seno del procedimiento legislativo varios principios constitucionales, entre ellos, el principio democrático y de respeto de las minorías.

\section{LA CONSTITUCIÓN POLÍTICA DE LA REPÚBLICA DE COSTA RICA DE 1949}

La Constitución Política de la República de Costa Rica fue promulgada el 7 de noviembre de 1949, y a la fecha lleva más de 50 reformas parciales. Sobre el particular, es evidente que el articulado de la Constitución constituye el primer elemento del bloque de constitucionalidad en el ordenamiento jurídico costarricense y, además, está dotado de plena normatividad, motivo por el cual es vinculante con respecto a los Poderes públicos.

Es claro entonces que en unos supuestos las disposiciones de la Constitución y su fuerza normativa se imponen de forma directa a las actuaciones y las omisiones de los Poderes constituidos, en otros casos es necesario realizar un proceso de concretización de las normas constitucionales a través de la interpretación, o bien un desarrollo legislativo ulterior con ese propósito. De ahí que no es similar la forma en que las distintas normas constitucionales vinculan a los Poderes constituidos. En consecuencia, los tribunales ordinarios, al resolver con autoridad de cosa juzgada formal y material un conflicto de intereses, aplican la ley y la Constitución, lo cual, lógicamente, implica un juicio previo de constitucionalidad y de convencionalidad sobre la norma legal que ha de ser interpretada en el caso particular. Dicho juicio preliminar se realiza con base en las disposiciones que en el ordenamiento jurídico costarricense integran el bloque de constitucionalidad. De esta forma, si la norma legal no supera el juicio preliminar de constitucionalidad o de convencionalidad realizado por el juez ordinario al pretender aplicar la ley, tiene la obligación de formular la consulta judicial de constitucionalidad como se ha comentado con anterioridad, de acuerdo con el art. 102 de la Ley de la Jurisdicción Constitucional, para que sea la Sala la que determine si esa disposición finalmente lesiona o no el derecho de la Constitución. Lo anterior, teniendo en consideración que el art. 10 de la Constitución Política le atribuye el monopolio del rechazo a la Sala Constitucional de la Corte Suprema de Justicia, para expulsar del ordenamiento jurídico toda disposición que vulnere el derecho de la 
Constitución. De otro lado, si los tribunales ordinarios, al efectuar el examen preliminar de constitucionalidad de las disposiciones legales, estiman que no lesionan el derecho de la Constitución, aplican al caso que deben juzgar tanto la Constitución como la ley, e incluso pueden efectuar una interpretación de la disposición legal conforme al derecho de la Constitución, siempre que no desborde los límites del mismo texto legal. De modo que la eficacia directa e inmediata del derecho de la Constitución supone, en palabras del magistrado Jinesta Lobo:

[...] que todos los jueces y tribunales ordinarios deben interpretarla y aplicarla (verbigracia, enjuiciamiento previo de la constitucionalidad de la norma aplicable, el que puede traducirse en un juicio positivo de constitucionalidad de la norma o acto aplicable al caso concreto, uno dubitativo fundado de constitucionalidad que desemboca en la consulta judicial de constitucionalidad; la aplicación de los principios y valores constitucionales que deben informar la práctica judicial —entre los que destaca el de interpretación conforme a la Constitución-, así como de la jurisprudencia de la Sala Constitucional que resulta vinculante erga omnes) (Jinesta Lobo, 2007: 230).

En todo caso, a todas luces es evidente la manera en que el derecho de la Constitución vincula la actividad de los órganos jurisdiccionales y de todas las autoridades públicas. En unos casos se impone de manera directa frente a la actuación de los Poderes públicos, en otros, precisa de un desarrollo normativo ulterior que dote a los preceptos constitucionales de eficacia plena. En estos últimos supuestos, la inactividad de los Poderes públicos en desarrollar los preceptos constitucionales de ejecución o de eficacia diferida puede dar lugar a una inconstitucionalidad por omisión, total o parcial, lo cual ha sido plenamente admitido en la jurisprudencia de la Sala Constitucional de la Corte Suprema de Justicia (fundamentalmente a partir de la conocida sentencia 2005-05649, de 11 de mayo, en la cual se resolvió la acción de inconstitucionalidad planteada contra la omisión del legislador de dotar de eficacia plena los mandatos establecidos en los arts. 105 y 123 de la Constitución Política, así como el transitorio único de la Ley 8281, de 28 de mayo de 2002, por cuyo medio se reformó parcialmente la Constitución para implementar varios mecanismos de democracia participativa -iniciativa popular y referéndum-, estableciéndose el plazo de un año para dictar las leyes de desarrollo, así como en la doctrina). Al respecto, si bien algún sector doctrinal se ha levantado contra la posibilidad de la Sala Constitucional (y, en términos más generales, de los tribunales constitucionales) de controlar la inactividad de las autoridades públicas que vulnera el derecho de la Constitución, por el contrario, en esta investigación se ha defendido que supone el mayor alcance 
del principio de supremacía de la Constitución. En este orden de ideas, Villaverde Menéndez ha sostenido sobre las tesis que han criticado el control de inconstitucionalidad por omisión que eluden «la más intensa legitimidad democrática del legislador puede explicar su preeminencia entre los Poderes del Estado y la superioridad de la ley respecto de las demás formas jurídicas del concreto ordenamiento jurídico, pero no ya su relación con la Constitución, regida únicamente por la supremacía normativa de esta última» (Villaverde Menéndez, 1997: 10). Es muy claro entonces que el legislador, al igual que los otros Poderes públicos, es un Poder constituido y, por ello, sus actos y sus omisiones son susceptibles de control por el Tribunal Constitucional, que lógicamente puede declararlos inconstitucionales si infringen un precepto de la Norma Fundamental. Cabe mencionar que la Constitución Política de la República de Costa Rica está integrada por XVIII títulos más las disposiciones transitorias ${ }^{16}$.

A diferencia del sistema francés, el preámbulo de la Constitución Política de la República de Costa Rica ${ }^{17}$ no está provisto de carácter normativo ni

16 Tales son: el título I: «La República»; el título II: «Los Costarricenses»; el título III: «Los Extranjeros»; el título IV: «Derechos y Garantías Individuales»; el título V: «Derechos y Garantías Sociales»; el título VI: «La Religión»; el título VII: «La Educación y la Cultura»; el título VIII: «Derechos y Deberes Políticos» (este título, a su vez, se divide en tres capítulos, que son: el capítulo I: «Los Ciudadanos»; el capítulo II: «El Sufragio», y el capítulo III: «El Tribunal Supremo de Elecciones»); el título IX: «El Poder Legislativo» (que, a su vez, se divide en tres capítulos: el capítulo I: «Organización de la Asamblea Legislativa»; el capítulo II: "Atribuciones de la Asamblea Legislativa», y el capítulo III: «Formación de las Leyes»); el título X: «El Poder Ejecutivo» (que está integrado por los siguientes capítulos: el capítulo I: «El Presidente y el Vicepresidente de la República»; el capítulo II: «Deberes y atribuciones de quienes ejercen el Poder Ejecutivo»; el capítulo III: «Los Ministros de Gobierno»; el capítulo IV: «El Consejo de Gobierno», y el capítulo V: «Responsabilidades de quienes ejercen el Poder Ejecutivo»); el título XI: «El Poder Judicial»; el título XII: «El Régimen Municipal»; el título XIII: «Hacienda Pública» (que, a su vez, está integrado por el capítulo I: «El Presupuesto de la República»; el capítulo II: «La Contraloría General de la República», y el capítulo III: «La Tesorería Nacional»); el título XIV: «Las Instituciones Autónomas»; el título XV: «El Servicio Civil»; el título XVI: «El Juramento Constitucional»; el título XVII: «Las Reformas de la Constitución», y el título XVIII: «Disposiciones Finales», para un total de 197 artículos.

17 El preámbulo de la Constitución Política de la República de Costa Rica dice lo siguiente: «Nosotros, los representantes del pueblo de Costa Rica, libremente elegidos diputados a la Asamblea Nacional Constituyente, invocando el nombre de Dios y reiterando nuestra fe en la democracia, decretamos y sancionamos la siguiente: Constitución Política de la República de Costa Rica». 
integra o compone el bloque de constitucionalidad. A lo sumo podría servir al juez constitucional como criterio de interpretación de las normas constitucionales (como cualquier otro método o criterio de interpretación: histórico, sistemático, literal, de concretización) y de los demás elementos que conforman el derecho de la Constitución. Además, la Constitución Política costarricense contiene una parte dogmática, de reconocimiento de los derechos fundamentales de que goza todo particular por su condición de ser humano, que no es taxativa y, por el contrario, es completada con los instrumentos internacionales sobre derechos humanos, que son directamente exigibles ante la Sala Constitucional de la Corte Suprema de Justicia, por ejemplo, mediante un recurso de amparo, o de habeas corpus, o por las diferentes alternativas de control de constitucionalidad, y que incluso la jurisprudencia de la Sala Constitucional les ha otorgado valor supraconstitucional si confieren mayores garantías o mayor nivel de tutela que la propia Constitución. Pero también está conformada la Constitución por una parte orgánica, en que se establece la configuración constitucional de los principales Poderes públicos. Entre los principios generales que informan el texto de la Constitución es posible mencionar los siguientes: el principio republicano, el principio democrático y el respeto de todos los valores que integran la dignidad humana.

Así, la Asamblea Legislativa es un órgano unicameral y se compone de 57 diputados, los cuales tienen ese carácter por la Nación y son elegidos por provincias. De esta forma, los diputados permanecen en sus cargos por períodos de cuatro años y no pueden ser reelectos en forma sucesiva ${ }^{18}$. Entre las funciones más importantes que la Constitución Política de la República de Costa Rica le asigna al Poder Legislativo, es preciso mencionar la de control político, así como la de dictar las leyes, reformarlas, derogarlas y darles interpretación auténtica, salvo lo dicho en el capítulo referente al Tribunal Supremo

18 Entre los requisitos para ser diputado, el art. 108 de la Constitución Política de la República de Costa Rica menciona los siguientes: ser ciudadano en ejercicio; ser costarricense por nacimiento, o por naturalización con diez años de residencia en el país después de haber obtenido la nacionalidad, y haber cumplido veintiún años de edad. Por su parte, el art. 109 constitucional establece las siguientes incompatibilidades para el ejercicio de la función legislativa: el presidente de la República o quien lo sustituya en el ejercicio de la presidencia al tiempo de la elección; los ministros de Gobierno; los magistrados propietarios de la Corte Suprema de Justicia; los magistrados propietarios y suplentes del Tribunal Supremo de Elecciones, y el director del Registro Civil; los militares en servicio activo; los que ejerzan jurisdicción, autoridad civil o de policía, extensiva a una provincia; los gerentes de las instituciones autónomas; los parientes de quien ejerza la presidencia de la República, hasta el segundo grado de consanguinidad o afinidad, inclusive. 
de Elecciones. Por su lado, en lo que atañe a la Jefatura del Estado y al Poder Ejecutivo, es preciso mencionar que es un órgano compuesto, que está integrado por cuatro órganos constitucionales, a saber, el presidente de la República (quien es jefe del Estado y jefe del Gobierno), los ministros de ramo, el Consejo de Gobierno y el Poder Ejecutivo en sentido estricto (entiéndanse el presidente de la República y el ministro de ramo correspondiente). De este modo, las funciones de quien ejerce la presidencia de la República han sido contempladas en el art. 139 de la Constitución Política ${ }^{19}$, mientras que los requisitos para ocupar ese cargo han sido contemplados en el art. 131 de la Constitución Política ${ }^{20}$. Por su parte, en lo que atañe a la figura del Poder Ejecutivo en sentido estricto (es decir, a la conjunción del presidente de la República y su ministro de ramo), sus funciones han sido contempladas en el art. 140 de la Constitución. De lo anterior, fácilmente se deduce que la Constitución Política costarricense ha preferido encomendar la mayor parte de las funciones que normalmente corresponden al Ejecutivo al órgano denominado Poder Ejecutivo en sentido estricto. De tal manera que, por ejemplo, si en la adopción de un decreto ejecutivo adoptado con arreglo al art. 140 inciso 3) de la Constitución Política ${ }^{21}$ se omitiese la firma del ministro de ramo que debía suscribir ese acto con el presidente de la República, ello necesariamente produciría la inconstitucionalidad del decreto en cuestión. Sobre los otros órganos que según la Constitución integran el Poder Ejecutivo también se recogen en la misma los requisitos que deben reunir los ministros, así como las funciones propias del Consejo de Gobierno.

19 El art. 139 de la Constitución Política de la República de Costa Rica dispone: «ARTÍCULO 139.- Son deberes y atribuciones exclusivas de quien ejerce la Presidencia de la República: 1) Nombrar y remover libremente a los Ministros de Gobierno; 2) Representar a la Nación en los actos de carácter oficial; 3) Ejercer el mando supremo de la fuerza pública; 4) Presentar a la Asamblea Legislativa, al iniciarse el primer período anual de sesiones, un mensaje escrito relativo a los diversos asuntos de la Administración y al estado político de la República y en el cual deberá, además, proponer las medidas que juzgue de importancia para la buena marcha del Gobierno, y el progreso y bienestar de la Nación 5) Comunicar de previo a la Asamblea Legislativa, cuando se proponga salir del país, los motivos de su viaje».

20 Dichos requisitos son: ser costarricense por nacimiento y ciudadano en ejercicio, ser del Estado seglar, y ser mayor de treinta años.

21 El art. 140 inciso 3) de la Constitución Política de la República de Costa Rica, dispone: «ARTÍCULO 140.- Son deberes y atribuciones que corresponden conjuntamente al Presidente y al respectivo Ministro de Gobierno: [... 3) Sancionar y promulgar las leyes, reglamentarlas, ejecutarlas y velar por su exacto cumplimiento». 
Asimismo, el art. 152 de la Constitución Política de la República de Costa Rica señala que el Poder Judicial se ejerce por la Corte Suprema de Justicia y por los demás tribunales que establezca la ley. Sobre el particular, el art. 154 constitucional establece que solo está sometido a la Constitución y a la ley. Además, y bajo la observancia del principio de independencia jurisdiccional, ningún tribunal puede avocar el conocimiento de causas pendientes ante otro, y solo se pueden solicitar los expedientes ad effectum videndi. La Corte Suprema de Justicia es el tribunal superior del Poder Judicial, y de ella dependen los tribunales, funcionarios y empleados en el ámbito judicial, y está conformada por veintidós magistrados, divididos en cuatro salas: cinco en la Sala Primera (que conoce asuntos civiles y contencioso-administrativos), cinco en la Sala Segunda (que conoce asuntos laborales y de familia), cinco en la Sala Tercera (que conoce asuntos penales) y siete en la Sala Constitucional ${ }^{22}$.

Finalmente, y de conformidad con lo dispuesto en el art. 99 de la Constitución Política de la República de Costa Rica, le corresponde al Tribunal Supremo de Elecciones la organización, dirección y vigilancia de los actos relativos al sufragio, el cual goza de independencia en el desempeño de su cometido. De esta forma, los magistrados de ese tribunal están sujetos a las condiciones de trabajo, y al tiempo mínimo de labor diaria que indique la Ley Orgánica del Poder Judicial para los Magistrados de la Sala de Casación, y percibirán las remuneraciones que se fijen para estos. Además, duran en sus cargos seis años, y gozan de las inmunidades y prerrogativas que corresponden a los miembros de los Supremos Poderes ${ }^{23}$. Por otra parte, es preciso resaltar lo

22 Cabe mencionar que los magistrados de la Corte Suprema de Justicia, incluyendo los de la Sala Constitucional, son electos por ocho años y se consideran reelegidos para períodos iguales, salvo que en votación no menor de las dos terceras partes del total de los miembros de la Asamblea Legislativa se acuerde lo contrario.

23 Este Tribunal tiene atribuidas constitucionalmente importantes, entre las que destacan, a efectos de nuestra investigación: convocar a elecciones populares (función administrativa electoral); interpretar en forma exclusiva y obligatoria las disposiciones constitucionales y legales referentes a la materia electoral (función normativa electoral), e investigar, por sí o por medio de delegados, y pronunciarse con respecto a toda denuncia formulada por los partidos sobre parcialidad política de los servidores del Estado en el ejercicio de sus cargos, o sobre actividades políticas de funcionarios a quienes les esté prohibido ejercerlas. La declaratoria de culpabilidad que pronuncie el Tribunal será causa obligatoria de destitución e incapacitará al culpable para ejercer cargos públicos por un período no menor de dos años, sin perjuicio de las responsabilidades penales que pudieren exigírsele. No obstante, si la investigación practicada contiene cargos contra el presidente de la República, ministros de Gobierno, ministros diplomáticos, contralor y subcontralor generales de la República, o magistrados 
dispuesto por el art. 103 de la Constitución Política de la República de Costa Rica, en el sentido de que las decisiones del Tribunal Supremo de Elecciones no tienen recurso, salvo la acción por prevaricato.

\section{LAS DISPOSICIONES DEL REGLAMENTO DE LA ASAMBLEA LEGISLATIVA QUE ESTABLECEN TRÁMITES SUSTANCIALES EN EL PROCEDIMIENTO DE FORMACIÓN DE LAS LEYES}

Ahora bien, en el ordenamiento jurídico costarricense el procedimiento de formación de las normas con rango de ley ha sido contemplado en los arts. 123 a 129 del Texto Fundamental, y es desarrollado por las disposiciones del Reglamento de la Asamblea Legislativa. En este sentido, el art. 73 de la Ley de la Jurisdicción Constitucional, en su inciso c), establece la posibilidad de entablar una acción de inconstitucionalidad contra una ley cuando durante su proceso de formación se haya violado algún requisito o trámite sustancial previsto en la Constitución o en el Reglamento de la Asamblea Legislativa.

De lo anterior se infiere, con toda claridad, que las disposiciones del Reglamento aludido eventualmente integran el derecho de la Constitución, si dentro del procedimiento legislativo establecen un trámite sustancial en el cual se desarrolle algún principio fundamental contemplado en la Constitución, como son los casos del principio democrático, el de respeto de las minorías, o publicidad, entre otros ${ }^{24}$.

de la Corte Suprema de Justicia, el Tribunal se concretará a dar cuenta a la Asamblea Legislativa del resultado de la investigación (función jurisdiccional electoral); y dictar, con respecto a la fuerza pública, las medidas pertinentes para que los procesos electorales se desarrollen en condiciones de garantías y libertad irrestrictas. En caso de que esté decretado el reclutamiento militar, podrá igualmente el Tribunal dictar las medidas adecuadas para que no se estorbe el proceso electoral, a fin de que todos los ciudadanos puedan emitir libremente su voto. Estas medidas las hará cumplir el Tribunal por sí o por medio de los delegados que designe (función normativa electoral); efectuará el escrutinio definitivo de los sufragios emitidos en las elecciones de presidente y vicepresidentes de la República, diputados a la Asamblea Legislativa, miembros de las municipalidades y representantes en Asambleas Constituyentes (función electoral); y hará la declaratoria definitiva de la elección de presidente y vicepresidentes de la República, dentro de los treinta días siguientes a la fecha de la votación.

24 Sobre lo anterior, la Sala Constitucional, en la sentencia No. 2002-11607, de 11 de diciembre, al resolver la acción de inconstitucionalidad planteada contra los arts. 468, 469, 470, 471, 473, 474, 477, 712, 713, 716, 721, 726, 728 del Código Fiscal, señaló: «I.- DE LA INCONSTITUCIONALIDAD DE LA LEY POR VIOLACIÓN AL TRÁMITE LEGISLATIVO. Conforme lo establece el inciso c) del artículo 73 la Ley 
Del contenido de la sentencia transcrita, claramente se deduce que las disposiciones del Reglamento de la Asamblea Legislativa constituyen parámetro de constitucionalidad si establecen algún trámite sustancial en el procedimiento de elaboración de las leyes o si desarrollan algún principio fundamental previsto en la Constitución como el democrático y el de publicidad.

\section{LOS INSTRUMENTOS INTERNACIONALES SOBRE DERECHOS HUMANOS}

A diferencia de los criterios sostenidos sobre el particular por el Consejo Constitucional francés y el Tribunal Constitucional español, en el sentido en que los instrumentos internacionales sobre derechos humanos no integran el parámetro o bloque de constitucionalidad, en el ordenamiento jurídico costarricense, en cambio, dichos instrumentos constituyen verdaderas reglas

de la Jurisdicción Constitucional, el Reglamento de Orden, Dirección y Disciplina Interior de la Asamblea Legislativa, constituye un parámetro de constitucionalidad en lo que se refiere a los requisitos o trámites sustanciales en el procedimiento de formación de leyes, acuerdos legislativos o cuando se suscriban, aprueben o ratifiquen convenios o tratados internacionales. A través de su jurisprudencia, esta Sala ha establecido que es competente para decretar la anulación de una ley o acuerdo legislativo si constata que en el procedimiento de su formación se violó algún trámite sustancial, previsto en la Constitución o en el Reglamento de la Asamblea Legislativa. En el presente asunto, acusa el accionante que si bien la ley que cuestiona sufrió los tres debates conforme al artículo 95 de la Constitución Política vigente a la promulgación de la norma, no respetó lo dispuesto en el artículo 42 del Reglamento de Orden, Dirección y Disciplina interior del Congreso Constitucional, según el cual: "Es a cargo de la Secretaría la forma y redacción de los decretos y demás disposiciones que emita el Congreso; pero todos ellos serán sometidos a su última aprobación, antes de ser firmados y despachados". Explica que de conformidad con la norma transcrita, cada proyecto debe contar con tres aprobaciones del mismo, aprobación que de las actas del expediente legislativo de la ley en cuestión, no consta se dio en los dos primeros debates del proyecto y únicamente aparece la última aprobación en tercer debate; lo que a su criterio invalida la norma. A criterio de este Tribunal, el que no se haya estipulado expresamente en las actas la aprobación del proyecto de ley en primero y segundo debate, no invalida el trámite legislativo porque no constituye un vicio o irrespeto del trámite legislativo del el que no conste en el acta que no se aprobó en el primero o segundo debate el citado proyecto, ya que el proceso de su discusión y aprobación final se realizó en resguardo del principio democrático y se cumplieron a cabalidad los procedimientos constitucionales y reglamentarios para su aprobación. En consecuencia, la omisión que acusa el accionante no existe y no produce el efecto invalidante de la ley dentro del trámite legislativo, que se pretende en la acción». 
jurídicas y son utilizados por la Sala Constitucional para valorar la conformidad de una disposición infraconstitucional con respecto al derecho de la Constitución.

Lo anterior es posible en virtud de una interpretación que sostiene que tales instrumentos, a diferencia de otras normas y reglas del derecho internacional, no tienen únicamente un valor superior a la ley de acuerdo con el art. 7..$^{\circ}$ de la Constitución Política de la República de Costa Rica, sino que sus disposiciones, en la medida en que brinden mayor cobertura o tutela de un determinado derecho, deben prevalecer sobre estos. De esta forma, lo que ha realizado la Sala Constitucional es una construcción a partir de los alcances del art. 48 de la Constitución Política (en cuya razón es posible plantear un recurso de amparo no solo por la vulneración de un derecho consagrado en la Constitución Política, sino también en un instrumento internacional sobre los derechos humanos), lo cual ha sido desarrollado por la Sala en reiteradas ocasiones ${ }^{25}$.

Cabe mencionar que los demás instrumentos internacionales, eventualmente, pueden ser utilizados por la Sala Constitucional como parámetro de constitucionalidad, sin que por ello integren el derecho de la Constitución o el bloque, teniendo en consideración lo dispuesto por el art. 73 inciso d) de la Ley de la Jurisdicción Constitucional, que establece la posibilidad de entablar una acción de inconstitucionalidad cuando alguna ley o disposición general infrinja el 7 párr $1 .^{\circ}$ de la Constitución, justamente por oponerse a un tratado público o convenio internacional ${ }^{26}$.

De otro lado, en lo que atañe al valor vinculante de la jurisprudencia de la Corte Interamericana de Derechos Humanos, la Sala Constitucional, tras una serie de fallos donde se negaba a admitir ese carácter, por medio de la sentencia No. 2014-12703, de 1 de agosto, puso de manifiesto la fuerza

25 Sobre el particular, es preciso consultar las siguientes decisiones: No. 1147-90, de 21 de septiembre, No. 1739-92, de 1 de julio, No. 3435-92, y su aclaración, No. 575993, No. 2313-95, de 9 de mayo, No. 2000-09685 de 1 de noviembre, No. 2002 10693, de 7 de noviembre, y No. 2007-1682, de 9 de febrero de 2007, las cuales serán comentadas en la última fase de mi investigación.

26 El art. 7 de la Constitución Política de la República de Costa Rica dispone: "ARTÍCULO 7.- Los tratados públicos, los convenios internacionales y los concordatos, debidamente aprobados por la Asamblea Legislativa, tendrán desde su promulgación o desde el día que ellos designen, autoridad superior a las leyes. Los tratados públicos y los convenios internacionales referentes a la integridad territorial o la organización política del país, requerirán aprobación de la Asamblea Legislativa, por votación no menor de las tres cuartas partes de la totalidad de sus miembros, y la de los dos tercios de los miembros de una Asamblea Constituyente, convocada al efecto». 
vinculante de estos precedentes, aunque la República de Costa Rica no sea parte del litigio que se trate, con sustento en la siguiente argumentación:

\begin{abstract}
III.- CARÁCTER VINCULANTE DEL CONTROL DE CONVENCIONALIDAD. El control de convencionalidad diseñado por la Corte Interamericana de Derechos Humanos (básicamente, a través de las sentencias en los casos Almonacid Arellano y otros c/. Chile de 26 de septiembre de 2006, Trabajadores Cesados del Congreso c/. Perú de 24 de noviembre de 2006, Cabrera García y Montiel Flores c/. México de 26 de noviembre de 2010 y Gelman c/. Uruguay de 24 de febrero de 2011) es de acatamiento obligatorio para las Salas y Tribunales Constitucionales, debiendo contrastar cualquier conducta (activa u omisiva) con el parámetro de convencionalidad o el corpus iuris interamericano, conformado por las convenciones y declaraciones regionales en materia de Derechos Humanos, la jurisprudencia de esa Corte y sus opiniones consultivas.
\end{abstract}

Dicho criterio, que no es compartido por todos los magistrados titulares que actualmente integran la Sala Constitucional, ha servido de base para afirmar el carácter vinculante de la jurisprudencia de la Corte IDH, sobre todo en aquellos casos en que la República de Costa Rica no es parte. Así, en el caso concreto, la Sala Constitucional se valió de los alcances de la sentencia dictada por la Corte IDH en el caso Atala Riffo y niñas vs. Chile, sentencia de 24 de febrero de 2012, en cuanto a la prohibición de discriminar en razón de la orientación sexual, y se obligó al Colegio de Abogados y Abogadas de Costa Rica a extender a la pareja del recurrente el carné para el ingreso y uso de las instalaciones de esa corporación profesional y, en caso de presentar las gestiones concretas, tramitar lo correspondiente para que pueda incluirlo como beneficiario de la póliza de vida y asegurado en las pólizas de los seguros voluntarios.

Cabe mencionar que con esta decisión la Sala Constitucional modificó el criterio vertido en la sentencia No. 2012-5590, de 2 de mayo de 2012, dictada en la acción de inconstitucionalidad interpuesta en contra de lo dispuesto en el art. 10 del Reglamento de Salud de la Caja Costarricense de Seguro - norma que definía como beneficiaria del seguro de salud a aquella persona de sexo distinto-, en donde la mayoría de la Sala consideró que no resultaba aplicable al tema del aseguramiento para parejas del mismo sexo lo resuelto en la sentencia dictada por la Corte IDH. Sobre el particular, aunque compartimos sin duda los alcances del fallo No. 2014-12703, de 1 de agosto, sobre todo en lo que respecta a la aplicación de la sentencia de la Corte IDH en el caso Atala Riffo y niñas vs. Chile, de 24 de febrero de 2012, sí nos parece conveniente proceder con cautela en esta materia, vigilar la jurisprudencia de la Corte IDH, y aplicarla en nuestro país solo si, en aplicación del principio pro homine, el estándar convencional es superior al nacional con respecto a 
determinado derecho. Es lógico entonces que ello depende, ciertamente, de la ponderación que realice el Tribunal Constitucional en determinado conflicto de derechos, con lo cual el principio de autocontención debe encontrarse de manera permanente en el actuar de los jueces constitucionales, quienes son los únicos facultados para expulsar del ordenamiento jurídico costarricense, con efectos erga omnes, una norma con rango de ley que se estime inconvencional, es decir, contraria al derecho de la Constitución o al bloque de constitucionalidad y de convencionalidad.

\section{CONCLUSIONES}

En este breve ensayo se han repasado el origen del bloque de regularidad constitucional y las normas que lo comprenden en los sistemas de justicia constitucionales francés y costarricense. Ahora bien, en lo que atañe a Costa Rica, dicho bloque de constitucionalidad se ha fortalecido con la inclusión, dentro de ese parámetro, de los instrumentos internacionales en materia de derechos humanos, con un valor supraconstitucional, de tal modo que prevalecen, incluso sobre la Constitución, si confieren mayores garantías o mayor nivel cobertura que los derechos que la Norma Fundamental.

En este nuevo paradigma, por obra de la fuerza normativa de la jurisprudencia de la Corte IDH, se ha impulsado el carácter vinculante del corpus iuris interamericano, de tal modo que se habla, en la actualidad, de un bloque o parámetro de constitucionalidad y de convencionalidad, cuya tutela o aplicación le corresponde, con carácter de monopolio, a la Sala Constitucional de la Corte Suprema de Justicia. Lo anterior no impide, sin embargo, y como se expuso con anterioridad, que el juez ordinario sea partícipe de dicho control paralelo de constitucionalidad y de convencionalidad. Se trata, en suma, de un examinar preliminar que realiza el juez ordinario en consonancia con la Constitución y los instrumentos internacionales en materia de derechos humanos, en cuya razón, puede incluso efectuar una interpretación de la normativa infraconstitucional acorde con dicho parámetro. No obstante, si al efectuar dicho examen previo el juez estima que la norma que debe aplicar es inconstitucional o inconvencional, debe promover la consulta judicial para que la Sala Constitucional efectúe el juicio último y definitivo de acuerdo con el parámetro aludido, y en atención al modelo hiperconcentrado de justicia constitucional que se desprende del art. 10 de la Constitución Política de la República de Costa Rica.

Mucho por discutir queda en ese ámbito. Un examen más profundo se espera efectuar en otra ocasión. 


\section{Bibliografía}

Aragón, M. (1999). Constitución y control de poder. Bogotá: Universidad Externado de Colombia.

Bon, P. (2002). A propósito del Consejo Constitucional Francés. En Memorias del Seminario de Justicia Constitucional y Derechos Humanos, homenaje al Dr. Rodolfo E. Piza Escalante. San José: Corte Interamericana de Derechos Humanos.

Favoreu, L. y Rubio Llorente F. (1991). El bloque de la constitucionalidad. En Simposium Franco-Español de Derecho Constitucional. Sevilla: Universidad de Sevilla; Civitas.

Fernández Rodríguez, J. J. (2003). La Justicia Constitucional Europea ante el siglo XXI. Madrid: Tecnos.

Fernández Segado, F. (2009). La justicia constitucional: una visión de derecho comparado. Tomo II, La justicia constitucional en Francia. Madrid: Dykinson.

Hernández Valle, R. (1993). Derecho de la Constitución, Volumen I-II. San José: Juriscentro.

Jinesta Lobo, E. (2007). Relaciones entre jurisdicción ordinaria y justicia constitucional. Anuario de Derecho Constitucional Latinoamericano, 1, 220-240.

Pardo Falcón, J. (1990). El Consejo Constitucional Francés, la Jurisdicción Constitucional en la Quinta República. Madrid: Centro de Estudios Constitucionales.

Requejo Rodríguez, P. (1997). Bloque de constitucional y bloque de la constitucionalidad. Oviedo: Servicio de Publicaciones de la Universidad de Oviedo.

Rivero, J. (1987). Le Conseil Constitutionnel et les Libertes. Paris: Économica.

Rousseau, D. (2010). Droit du Contentieux Constitutionnel. Paris: Montchrestien.

Roussillon, H. (2004). Le Conseil Constitutionnel. Paris: Dalloz.

Rubio Llorente. F. (1997). La forma del poder: estudios sobre la Constitución. Madrid: Centro de Estudios Constitucionales.

Solano Carrera, L. F. (1995). La aplicación directa de la Constitución (el caso de Costa Rica). Revista Judicial, 19 (61), 25-40.

Villaverde Menéndez, I. (1997). La inconstitucionalidad por omisión. Madrid: McGraw-Hill. 